\title{
Influence of radar frequency on the relationship between bare surface soil moisture vertical profile and radar backscatter
}

\author{
M. Zribi ${ }^{1}$, A. Gorrab ${ }^{1-2}$, N. Baghdadi ${ }^{3}$, Z. Lili-Chabaane ${ }^{2}$, B. Mougenot $^{1}$ \\ 1- CESBI0, 18 av. Edouard Belin, bpi 2801, 31401 Toulouse cedex 9, France \\ 2- INAT, 43, Avenue Charles Nicolle 1082 -Tunis- Mahrajène TUNISIE \\ 3- IRSTEA, UMR TETIS, 500 rue François Breton, 34093 Montpellier cedex 5, France
}

\begin{abstract}
The aim of this paper is to discuss the influence of radar frequency on the relationship between surface soil moisture and the nature of radar backscatter over bare soils. In an attempt to address this issue, the Advanced Integral Equation Model (AIEM) was used to simulate backscatter from soil surfaces with various moisture vertical profiles, for three frequency bands: L, C and X. In these computations, we investigated the influence of the vertical heterogeneity of soil moisture on the characteristics of the backscattered signals. The influence of radar frequency is clearly demonstrated. A database produced from Envisat ASAR and TerraSAR-X data, acquired over bare soils with in situ measurements of moisture content and ground surface roughness, was used to validate the utility of taking the soil moisture heterogeneity into account in the backscatter model.
\end{abstract}

Key words: SAR, AIEM, soil moisture profile, bare soil 


\section{Introduction}

Soil moisture plays a key role in hydrological and climatic studies. Considerable efforts have been devoted to the study of radar backscatter responses from natural surfaces in active microwave remote sensing [1-5]. Electromagnetic analytical backscatter models (Kirchhoff models, the small perturbation method, and more recently the Integral Equation Model (IEM, [5]), the AIEM [6], ...) have been used to estimate soil moisture. However, various experimental measurements have shown that their use must be restricted to specific conditions. To reduce the discrepancy between these models and real data, various improvements have been made in the description of roughness, for example by introducing multi-scale approaches [7-8] and generalized power law spectra [9]. Over the past decade, new numerical methods have also made it possible to improve understanding of backscatter phenomena [10-11].

Simultaneously, various empirical approaches have been proposed, allowing the operational use of radar signals for the estimation of soil moisture. In this context, when the soil moisture is between approximately $10 \%$ and $35 \%$, a linear relationship is often observed between surface moisture and the strength of the backscattered signal [12-14]. This is generally considered to be approximately true for this range of soil moistures for a given study site. However, this linear relationship is not observed for surface backscatter models using surface roughness parameters and a dielectric constant corresponding to homogeneous soil. Instead, it is replaced by a relationship that saturates at soil moisture values of approximately $25 \%[1,5]$.

Soil moisture is often considered to have a homogeneous vertical profile. For studies in the L, C, and $\mathrm{X}$ frequency bands, empirical and semi-empirical models are often calibrated using soil samples collected down to a depth of $5 \mathrm{~cm}$, in which the moisture content is assumed to be homogeneous. In recent years, some studies have revealed that using the actual, inhomogeneous soil moisture profile can make a significant difference in the results obtained from backscatter models [15-17]. Fung et al. 
[15] have shown that discrepancies greater than $2 \mathrm{~dB}$ can occur in backscatter simulations, depending on whether the moisture is assumed to be homogeneous or to vary as a function of depth. Le Morvan et al. [17] found a limited effect in humid regions, where the soil moisture profile is characterised by relatively small variations. In semi-arid regions, the moisture content can vary quite strongly as a function of depth, due to the high ambient rate of evaporation and the small number of rainfall events [18]. Amri et al. [18] considered the moisture profile to be the primary reason for the observed discrepancies between ground-truth soil moisture measurements and remote sensing retrievals, using Vienna University's METOP ASCAT inversion approach [19]. Concurrent with these discussions, various algorithms based on either physical models, or statistical or empirical analyses, have been developed in recent years to estimate soil moisture [20-22]. A variety of global moisture products have also been proposed in recent years, using passive and active microwave satellite data (WSC ERS, MetOp ASCAT, Aqua AMSR-E, etc.) [23]. It is important to have a clear and precise understanding of the quantities estimated with each dataset and inversion technique. In particular, it is essential to take into account frequency differences between different datasets and their impact on retrieved moisture values.

The aim of the present paper is to propose an approach based on the AIEM model, in which the vertical soil moisture profile is taken into account. In Section 2 we present computations of Fresnel coefficients and penetration depth for a heterogeneous vertical soil moisture profile. In Section 3, we present AIEM model simulations using the proposed dielectric model, in which the influence of frequency is also considered. In Section 4 we propose an approach allowing these simulations to be validated using actual radar measurements (Envisat ASAR and TerraSAR-X) over bare soil test fields. Finally, conclusions are presented in Section 5.

\section{Analysis of the soil moisture profile}

\subsection{Computation of the Fresnel coefficients}


To analyze the influence of a non-uniform vertical soil moisture profile on backscatter simulations, we introduce the notion of a multi-layer soil surface, leading to dielectric constant variations as a function of depth. We estimated the soil's effective permittivity on the basis of the Fresnel coefficients determined for the interfaces between adjacent layers [15]. This effective permittivity is used as an input to the AIEM model, through the computation of a global Fresnel coefficient. In this study, we consider four layers $(0-1 \mathrm{~cm}, 1-2 \mathrm{~cm}, 2-3 \mathrm{~cm}$ and a deeper layer, extending below $3 \mathrm{~cm})$ for soil characterization. This distribution was chosen because, as a consequence of the evaporation process, the largest variations are generally observed in the first $3 \mathrm{~cm}$ of depth [17]. The coefficients $R_{3}, R_{2}, R_{1}$ and $R_{0}$ are the Fresnel coefficients at the boundaries among the four layers.

In the following, we provide an example of the computations used in the case of horizontal polarization only. In practice, we found very similar results for horizontal and vertical polarizations. The Fresnel reflection coefficient, $R_{0}$, between the air and layer 1 (with permittivity $\varepsilon_{1}$ ) is written:

$$
R_{0}^{h}=\frac{\cos \theta_{i}-\sqrt{\varepsilon_{1}-\sin ^{2} \theta_{i}}}{\cos \theta_{i}+\sqrt{\varepsilon_{1}-\sin ^{2} \theta_{i}}}
$$

where $\theta_{\mathrm{i}}$ is the incidence angle.

The Fresnel coefficient $R_{\mathrm{n}-1}$ between layer n-1 and layer n (permittivity $\varepsilon_{\mathrm{n}}$ ) is:

$$
R_{n-1}^{h}=\frac{\sqrt{\varepsilon_{n-1}-\sin ^{2} \theta_{i}}-\sqrt{\varepsilon_{n}-\sin ^{2} \theta_{n-1}}}{\sqrt{\varepsilon_{n-1}-\sin ^{2} \theta_{i}}+\sqrt{\varepsilon_{n}-\sin ^{2} \theta_{n-1}}}
$$

in which the angle of transmission $\theta_{n}$ defined by Snell's Law is given by:

$$
\sin ^{2} \theta_{n}=\frac{\varepsilon_{n-1}}{\varepsilon_{n}} \sin ^{2} \theta_{n-1}
$$

The half-space reflection coefficient for a layer of depth $d_{\mathrm{n}-1}$ is written: 
$R_{n-1, n}\left(\theta_{i}\right)=\frac{R_{n-1}\left(\theta_{i}\right)+e^{j 2 \psi_{n-1}} R_{n}\left(\theta_{i}\right)}{1+e^{j 2 \psi_{n-1}} R_{n-1}\left(\theta_{i}\right) R_{n}\left(\theta_{i}\right)}$

where $\psi_{n-1}$ is an attenuation factor depending on the thickness $d_{\mathrm{n}}$ of the $\mathbf{n t h}$ layer, the electromagnetic wavelength, $\lambda_{0}$, and the effective permittivity $\varepsilon_{\mathrm{n}}$ :

$\psi_{n-1}=\frac{2 \pi d_{n}}{\lambda_{0}} \sqrt{\varepsilon_{n}-\sin ^{2} \theta_{n-1}}$

In reality, there are no physical boundaries between the layers, and the soil medium has a continuous dielectric profile. To avoid standing wave effects resulting from the assumption of discrete layers, it was chosen to use incoherent analysis of the reflections in (4) [15]. The phase terms were thus neglected. The corresponding effective permittivity was computed from the retrieved Fresnel coefficient $R_{\text {tot }}$ by considering the case for which the incident waves impinge on all layers at normal incidence:

$\varepsilon_{\text {eff }}=\left(\frac{1+R_{\text {tot }}(0)}{1-R_{\text {tot }}(0)}\right)^{2}$

\subsection{Penetration depth computation}

The penetration depth $\delta \mathrm{p}$ of the radar wave is defined as the depth at which the power of the incident wave $\left(P_{0 p}\right)$ is reduced by a factor of e, $[1,24-25]$. In homogeneous soil, the power $P_{p}$ transmitted at a depth $d$ can be expressed as:

$$
P_{p}=P_{0 p} * \gamma_{1, p} * e^{-2 j k_{1 z} d}
$$

where $\gamma_{1, p}$ is the transmissivity, i.e. the Fresnel power coefficient at the interface between air and the soil surface; the exponential factor is the propagation factor in the soil. $k_{1 z}$ is the $z$ component of the wave number in soil: 
where $\omega$ is the radian frequency, $\mu_{0}$ is the permeability of air, $\varepsilon_{0}$ is the absolute permittivity of air, $\varepsilon_{i}$ is the complex relative permittivity of layer $\mathrm{i}, \theta_{i}$ is the incidence angle at the air-soil interface, and $\mathrm{K}$ is the wave number.

For the case of a multi-layer profile, the power transmitted into nth layers can be calculated using:

$$
P_{p}=P_{0 p} * \prod_{i=1}^{n-1} \gamma_{i, p} * e^{-2 j k d_{i}}
$$

where $d_{i}$ is the thickness of layer $i$, and $\gamma_{i-1, p}$ is the transmissivity of the interface between layers $i-1$ and i.

By assuming that $P_{p} / P_{0 p}=1 / e$ in (9), it follows that the penetration depth $\delta$ p corresponds to the depth of layer $n$, defined by the equality:

$$
\prod_{i=2}^{n} \gamma_{i-1, p} * e^{-2 j k_{i 2} d_{i}}=e^{-1}
$$

\subsection{Generation of simulated soil moisture profiles}

To analyze radar backscatter from surfaces with a heterogeneous vertical soil moisture profile, we simulated six different vertical moisture profiles, representing the influence of variations in soil moisture with depth following a rainfall event, as a function of time. Fig. 1 illustrates these six profiles, as a function of depth between 0 and $5 \mathrm{~cm}$. The first profile (Prof1) corresponds to homogeneous soil with a volumetric moisture content equal to $30 \%$. For the five other profiles, the soil moisture can be seen to decrease progressively from its maximum value at $5 \mathrm{~cm}$ to a minimum value at the surface, as a result of evaporation effects. The last profile (Prof 6) corresponds to nearly 
homogeneous soil moisture characterized by a volumetric moisture content close to $7 \%$. For all profiles, we considered the soil moisture to be homogeneous at depths greater than $5 \mathrm{~cm}$.

To simplify the scenarios discussed in this study, in agreement with Section 2.1 we consider each soil profile to have four layers, with the first from 0 to $1 \mathrm{~cm}(\mathrm{~d} 1=1 \mathrm{~cm})$, the second from 1 to $2 \mathrm{~cm}$ $(\mathrm{d} 2=1 \mathrm{~cm})$, the third from 2 to $3 \mathrm{~cm}(\mathrm{~d} 3=1 \mathrm{~cm})$, and the fourth for all depths below $3 \mathrm{~cm}$.

Fig. 2 illustrates the results of penetration depth computations based on the proposed four-layer distribution, for three frequency bands $(\mathrm{L}=1.25 \mathrm{GHz}, \mathrm{C}=5.3 \mathrm{GHz}$, and $\mathrm{X}=9.65 \mathrm{GHz})$, and the six simulated moisture profiles. The penetration depth clearly increases as the soil moisture content or the radar frequency is decreased. It is also important to note that the assumption 1 of a uniform value of $5 \mathrm{~cm}$ for the penetration depth is not consistent with the results found in this study. In fact, for the range of soil moisture profiles considered in this study, the mean penetration depths are found to be approximately $6 \mathrm{~cm}, 2.2 \mathrm{~cm}$ and $1 \mathrm{~cm}$ at L, C and $\mathrm{X}$ bands, respectively.

In the following section, we discuss the influence of multi-layer moisture profiles on the radar backscatter predicted by AIEM simulations.

\section{AIEM model simulations}

\subsection{Comparison between AIEM simulations using four-layer and single-layer configurations}

Fig. 3 compares AIEM simulations derived with two different configurations: (1) a four-layer moisture content profile with incorporation of penetration depth and (2) a single layer with homogeneous soil moisture equal to the mean value determined for the first $5 \mathrm{~cm}$. The six profiles presented in the previous section were used. The backscatter simulations were performed in $\mathrm{HH}$ polarization at the three frequencies corresponding to the $\mathrm{L}, \mathrm{C}$ and $\mathrm{X}$ bands, with an rms soil height equal to $0.6 \mathrm{~cm}$, a correlation length equal to $6 \mathrm{~cm}$, and an exponential correlation function. The corresponding texture is composed of about $30 \%$ sand, $40 \%$ clay and $30 \%$ silt. The input moisture values were taken to be the mean values computed from simulated moisture profiles for each respective layer $(0-5 \mathrm{~cm}, 0-1 \mathrm{~cm}, 1-2 \mathrm{~cm}, 2-3 \mathrm{~cm}$, etc.). The dielectric constant of each layer, which 
is a function of the volumetric moisture and texture, was computed using the algorithm proposed by Hallikainen et al. [26]. In Figs. 3a, 3b and 3c, corresponding to the three frequencies of interest, the coordinates of each point correspond to the simulated signal strengths found for a single layer (ordinate axis), and each of the six 4-layer soil moisture simulations (abscissa axis). Errors resulting from the use of a single-layer description are clearly small for high and low moisture values, for which it can generally be assumed that the soil profile is nearly homogeneous after prolonged consistent meteorological condition [17-18]. However, for the other cases corresponding to intermediate soil moisture content, the discrepancy between the simulated signal strengths can be greater than $2 \mathrm{~dB}$.

The rms error for the two types of simulation (4-layer AIEM model simulations and AIEM simulations with homogeneous conditions) is $0.97 \mathrm{~dB}$ at $\mathrm{L}$ band, $1.3 \mathrm{~dB}$ at $\mathrm{C}$ band and $1.3 \mathrm{~dB}$ at $\mathrm{X}$ band.

\subsection{Relationship between soil moisture and simulated radar backscatter}

Fig. 4 shows the relationships between soil moisture and simulated radar backscatter at a $20^{\circ}$ angle of incidence at the three frequencies: $1.25 \mathrm{GHz}$ (Fig. 4a), $5.3 \mathrm{GHz}$ (Fig. 4b) and $9.65 \mathrm{GHz}$ (Fig. 4c), for the same six simulated profiles. Each point in this figure corresponds to the AIEM-computed value, corresponding to one simulated profile. Three sets of simulations are associated with each of these figures: the first (Case 1) consists of AIEM four-layer simulations for each of the three frequencies as a function of soil moisture estimated between the surface and a penetration depth with variable moisture content; the second (Case 2) corresponds to simulations using a four layer model as a function of soil moisture content estimated as an average over the first $5 \mathrm{~cm}$ in depth; and the third (Case 3) corresponds to AIEM simulations made for a single-layer soil moisture profile estimated as an average over the first $5 \mathrm{~cm}$ in depth.

These results lead to three conclusions. First, a nearly linear relationship is found, as shown in Fig. 4, between the soil moisture estimated at a depth average over top $5 \mathrm{~cm}$ and the AIEM multi-layer 
model (Case 2), for soil moistures between $7 \%$ and $30 \%$. This linear relationship is not consistent with physical backscatter models for which homogeneous soil moisture conditions are assumed, as shown by various theoretical studies $[1,5]$ and our own simulations (Case 3). Using physical analytical models, a logarithmic relationship is generally retrieved, which tends to saturate at soil moisture values greater than 25\%. Single-layer model simulations (Case 3) show that the signals are over-estimated at intermediate values of soil moisture. This result is validated by almost all experimental studies $[13,20]$.

Second, we observe that the L-band frequency has the smallest discrepancies between different model simulations (Case 1, Case 2 and Case 3). This result is also consistent with other experimental and theoretical results, showing that there is a smaller discrepancy between the real data and model simulations at L band [27]. This behavior is partially due to the fact that L band has the greatest penetration depth, which is close to the $5 \mathrm{~cm}$ reference depth for medium moisture values, as shown in Fig. 2. The X-band frequency has the largest difference between cases. This implies that at X band there is a high risk of errors being introduced through the use of theoretical backscatter models if soil moisture heterogeneities are not taken into account in the dielectric constant estimation. Finally, the results based on theoretical models indicate that significant discrepancies can exist with a linear relationship often assumed in empirical inversion techniques at $\mathrm{C}$ and $\mathrm{X}$ bands. This effect could have significant impact on soil moisture retrieval for large vertical gradient in soil moisture, such as those observed under certain specific meteorological conditions, for example under high evaporation conditions. In fact, most empirical approaches (e.g. change detection methodology and/or a simple relationship between data and ground measurements) use a linear relationship for the soil moisture estimation consistent with Case 2 simulations, as opposed to other methods based on physical backscatter models, which often assume the soil moisture conditions to be homogeneous (Case 3). The consistency observed between the empirical relationships and Case 2 can be explained by the fact that the latter scenario produces almost the same conditions as an empirical approach based on 
radar simulations in which the actual soil heterogeneity is taken into account. Under these conditions, the estimated value of the soil moisture content estimated as an average over the first $5 \mathrm{~cm}$ in depth is taken as the second variable in the empirical relationship.

\section{Experimental discussions}

\subsection{Experimental data base}

a) Study site

Our study area is located in central Tunisia $\left(9^{\circ} 23^{\prime}-10^{\circ} 17^{\prime} \mathrm{E}, 35^{\circ} 10^{\prime}-35^{\circ} 55^{\prime} \mathrm{N}\right)$. The climate in this region is semi-arid, with an average annual rainfall of approximately $300 \mathrm{~mm} /$ year, characterized by a rainy season lasting from October to May, with the two rainiest months on average being October and March. As is generally the case in semi-arid areas, the rainfall patterns in this area are highly variable in time and space. The landscape is mainly flat, and the vegetation is dominated by agricultural production (cereal grains, olive groves, fruit trees, and market gardens).

b) Satellite database

Radar measurements were acquired with two sensors, Envisat ASAR (C-band, $5.6 \mathrm{~cm})$ and TerraSAR-X (X-band, $3.1 \mathrm{~cm})$. In the case of the ASAR data, the 'narrow mode' corresponding to high resolution data (pixel spacing $12.5 \mathrm{~m}$ x $12.5 \mathrm{~m}$ ) was chosen. The ASAR data was acquired over the study site using the configurations described in Table 1. Two TerraSAR-X images were acquired at high incidence angle $\left(35^{\circ}\right)$, at $\mathrm{HH}$ polarization and a ground pixel spacing of $1 \mathrm{~m}$ (Table 1 ). Following radiometric calibration of the radar images, they were geo-referenced using a SPOT/HRV optical image. The registration error of the ASAR and TerraSAR-X images is taken into account by selecting areas of interest (AOI) within each training site and removing two pixels corresponding to the limits defined by the GPS control points. Finally, the mean radar signals were estimated over the test fields for all of the measurement dates used in this analysis.

c) Ground truth measurements 
The field campaigns described in this study were performed in three bare training fields (F1, F2 and F3). Concurrent with the radar measurements, ground-truth measurements of soil roughness, moisture content, bulk density, and texture were made on the three test fields. The last three variables are needed to estimate the soil's dielectric constant.

\section{Soil moisture:}

Soil moisture measurements were performed to estimate soil moisture profiles within the top $5 \mathrm{~cm}$ (0-1 cm, 1-2 cm, 2-5 cm), using a gravimetric method with more than ten samples per field. These samples were collected using metallic cylinders of different length $(1 \mathrm{~cm}$ and $3 \mathrm{~cm})$, to retrieve volumetric soil moisture, the product of the moisture content and the soil density.

On each date, measurements were performed for each of the three tested fields. Fig. 5 illustrates various volumetric soil moisture profiles measured during the experimental campaigns. It can be clearly seen that the hypothesis of a uniform soil moisture profile is valid only for large values of soil moisture. In most other cases, the soil moisture is found to increase with increasing depth. We observed more than $10 \%$ difference in volumetric moisture between the first layer $(0-1 \mathrm{~cm})$ and the third $(2-5 \mathrm{~cm})$ layer.

Soil Texture: For each test field, several soil samples were taken and processed in the laboratory. Only small differences in texture were found among the three fields, and the mean values were $39 \%$ for sand, $41 \%$ for clay and $20 \%$ for silt (Table 2).

Soil Roughness: Soil roughness measurements were made using a pin profiler, with a total length of $1 \mathrm{~m}$ and a resolution of $2 \mathrm{~cm}$. In order to improve the accuracy of the roughness computations, approximately ten profiles were recorded for each field. Since the surface height profile is considered to be ergodic and stationary, we can compute an exponential correlation function for each profile and derive two statistical parameters: the rms surface height (vertical scale of roughness) and the correlation length $(l)$. The rms height ranged between 1.1 and $1.9 \mathrm{~cm}$, and the correlation length ranged between 3.8 and $6.1 \mathrm{~cm}$, as shown in Table 2 . 


\subsection{Comparison between AIEM simulations and measured radar signals}

Fig. 6 compares simulations performed using the AIEM model (multi-layer and single-layer configurations) with the real radar data acquired by Envisat ASAR (Fig. 6a) and TerraSAR-X (Fig. 6b). As a consequence of the large range of incidence angles over which Envisat ASAR data is collected (from IS1 to IS5) and the large variations in ground soil moisture, this data is characterized by a greater range of values than that obtained with TerraSAR, using a fixed angle of incidence. As also observed in other studies $[17,26]$, the single-layer AIEM simulations were found to underestimate the measured radar data, characterized by a bias and an rms error, respectively, of 1.4 $\mathrm{dB}$ and $2.2 \mathrm{~dB}$ for $\mathrm{C}$ band, and $2.8 \mathrm{~dB}$ and $2.7 \mathrm{~dB}$ for $\mathrm{X}$ band. The multi-layer simulations provided improved results, with good agreement between simulations and real data for $\mathrm{C}$ and $\mathrm{X}$ bands. The bias and RMSE were $0.5 \mathrm{~dB}$ and $1.3 \mathrm{~dB}$, respectively, for $\mathrm{C}$ band, and $0.8 \mathrm{~dB}$ and $1.0 \mathrm{~dB}$, respectively, for $\mathrm{X}$ band. These results have also revealed some of the limitations of the AIEM model, as has already been demonstrated by [11], from comparison with results determined with the NMM3D technique.

\section{Conclusions}

In this paper, we illustrate the influence of moisture profile heterogeneities on the backscattered radar signal. The AIEM multi-layer model is shown to produce different results from the AIEM single layer model, in the case of heterogeneous profiles, in particular those having a moderate level of soil moisture. A clearly linear relationship was established between the multi-layer model and the moisture estimates taken at a depth of $5 \mathrm{~cm}$, in the three frequency bands of interest (L, C and X). This linear relationship between the multi-layer model and the moisture content becomes non-linear for soil moisture estimates made at the penetration depth, as well as for simulations of homogeneous conditions. Linear behavior is generally observed in real data. Relationships between moisture and backscatter simulations were observed as a function of frequency and moisture heterogeneity. The 
least significant influence of moisture profile heterogeneities was found at $\mathrm{L}$ band. This is due to the fact that that the L-band penetration depth is approximately $5 \mathrm{~cm}$ for medium moisture levels, whereas the penetration depth for the $\mathrm{C}$ and $\mathrm{X}$ bands is around $1 \mathrm{~cm}$. A large difference for the $5 \mathrm{~cm}$ volumetric soil moisture exists if the moisture profile is heterogeneous.

Analysis of radar data measured by Envisat ASAR and TerraSAR-X in C and X bands confirms our theoretical results, with the rms error between simulations and data being improved to $1.3 \mathrm{~dB}$ and 1.0 $\mathrm{dB}$ for the multi-layer model, as opposed to $2.2 \mathrm{~dB}$ and $2.7 \mathrm{~dB}$ for the single-layer model, in $\mathrm{C}$ and $\mathrm{X}$ bands, respectively. These results confirm the significant influence of soil moisture heterogeneities on the strength of radar backscatter. They also highlight the sensitivity of inversion techniques and the dependence of the accuracy of retrieved soil moisture on the assumed moisture profile and the radar frequency, the latter being directly related to the penetration depth of radar waves. 


\section{References}

[1] F. T. Ulaby, M. K. Moore, A. K. Fung, Microwave Remote Sensing, Active and Passive. Artech House: Norwood, MA, 1986; vol. 3.

[2] T. J. Jackson, J. Schmugge, E. T. Engman, "Remote sensing applications to hydrology: soil moisture," Hydrol. Sci., vol. 41, pp. 517-530, 1996.

[3] M. Zribi, M. Dechambre, “A new empirical model to retrieve soil moisture and roughness from Radar Data," Remote Sens. Environ., Vol. 84, pp. 42-52, 2003.

[4] N. Baghdadi, M. Zribi, C. Loumagne, P. Ansart, T. Paris Anguela, Analysis of TerraSAR-X data and their sensitivity to soil surface parameters, Remote Sensing of Environment, Vol. 112, Issue $12,4370-4379,2008$.

[5] A. K. Fung, Z. Li, K. S. Chen, "Backscattering from a randomly rough dielectric surface,"IEEE Trans. Geosci. Remote Sens., vol. 30, pp. 356-369, 1992.

[6] K. S. Chen, T. D. Wu, L. Tsang, Q. Li, Shi, J., and A. K. Fung, ”Emission of rough surfaces calculated by the integral equation method with comparison to three-dimensional moment method simulations," IEEE Trans. Geosci. Remote Sens., vol. 41, pp. 90-101, 2003.

[7] M. Zribi, V. Ciarletti, O. Taconet, "Validation of a rough surface model based on fractional brownian geometry with SIRC and ERASME radar data over Orgeval site," Remote Sens.Environ., vol. 73, pp. 65-72, 2000.

[8] N. E. C. Verhoest, H. Lievens, W. Wagner, J. Alvarez-Mozos, M. S. Moran, and F. Mattia, “On the soil roughness parameterization problem in soil moisture retrieval of bare surfaces from Synthetic Aperture Radar,” Sensors, vol. 8, pp. 4213-4248, 2008.

[9] Q. Li, J. C. Shi, and K. S. Chen, “A generalized Power Law Spectrum and its Applications to the Backscattering of soil surfaces Based on the Integral Equation Model," IEEE Trans.Geosci. Remote Sens., vol. 40, pp. 271-281, 2002.

[10] P. Xu and L. Tsang, "Scattering by rough surface using a hybrid technique combining the multilevel UV method with the sparse-matrix canonical grid method," Radio Sci., vol. 40, no. 4, p. RS4 012, 2005.

[11] S. Huang, L. Tsang, Eni G. Njoku and K. S. Chan, "Backscattering coefficients, coherent reflectivities, and emissivities of randomly rough soil surfaces at L-Band for SMAP applications based on numerical solutions of Maxwell equations in 1 Three-Dimensional simulations," IEEE Trans. Geosci. Remote Sens., vol. 48, no. 6, pp. 2557-2568, 2010. 
[12] S. Le Hégarat-Mascle, M. Zribi, F. Alem, and A. Weisse, "Soil moisture estimation from ERS/SAR data: Toward an operational methodology," IEEE Trans. Geosci. Remote Sens., vol. 40, pp. 2647- 2658, 2002.

[13] Zribi, M., Saux-Picart, S., André, C., Descroix, L., Ottlé, O., Kallel, A., "Soil moisture mapping based on ARSAR/ENVISAT radar data over a sahelian site", 2007, International Journal of remote Sensing, 28, 16, 3547-3565.

[14] M. Aubert, N. Baghdadi, M. Zribi, K. Ose, M. El Hajj, I. Braud, and E. Vaudour, “Operational bare soil moisture mapping using TerraSAR-X data acquired over agricultural areas," IEEE Journal of Selected Topics in Applied Earth Observations and Remote Sensing, in press, 2012.

[15] A. K. Fung, J. B. Boisvert, and B. Brisco, "Interpretation of radar measurements from rough soil surface with a permittivity profile," Int. Geoscience And Remote Sensing Symposuim, vol. 3, pp. 1376-1378, 1997.

[16] J. B. Boisvert, Q. H. J. Gwyn, A. Chanzy, D. J. Major, B. Brisco, and R. J. Brown, "Effect of surface soil moisture gradients on modeling radar backscattering from bare fields," International Journal of Remote Sensing, vol. 18, no. 1, pp. 153-170, 1997.

[17] A. Le Morvan, M. Zribi, N. Baghdadi, and A. Chanzy, "Soil moisture profile effect on radar signal measurement," Sensors, vol. 8, pp. 256-270, 2008.

[18] R. Amri, M. Zribi, Z. Lili-Chabaane, W. Wagner, and S. Hauesner, "Analysis of ASCAT-C band scatterometer estimations derived over a semi-arid region," IEEE Trans. Geosci. Remote Sens., vol. 50, 7, Part I, pp. 2630-2638, 2012.

[19] W. Wagner, "Soil Moisture Retrieval from ERS Scatterometer Data," PhD dissertation, Vienna University of Technology, Austria, 1998.

[20] M. S. Moran, D. C. Hymer, J. Qi, and E. E. Sano, "Soil moisture evaluation using multitemporal synthetic aperture radar (SAR) in semiarid rangeland," Agric. Forest Meteorol., 27 vol. 105, pp. 69-80, 2000.

[21] M. S. Moran, C. D. Peters-Lidard, J. M. Watts, and S. McElroy, "Estimating soil moisture at the watershed scale with satellite-based radar and land surface models," Can. J. Remote Sens., vol. 30, pp. 805-826, 2004.

[22] S. B. Kim, L. Tsang, J. T. Johnson, S. Huang, J. J. van Zyl, and E. G. Njoku, "Soil moisture retrieval using Time-series radar observations over bare surfaces," IEEE Trans. Geosci.Remote Sens., vol. 50, no. 5, pp. 1853-1863, 2012. 
[23] C. Gruhier, P. De Rosnay, S. Hasenhauer, T. Holmes, R. De Jeu, Y. Kerr, E. Mougin, E. Njoku, F. Timouk, W. Wagner, and M. Zribi, "Soil moisture active and passive microwave products: intercomparison and evaluation over a Sahelian site," Hydrol. Earth Syst. Sci., vol. 14, pp. 141$156,2010$.

[24] L. Bruckler, H. Wittono, and P. Stengel, "Near surface moisture estimation from microwave measurements," Remote Sens. Environ., vol. 26, pp. 101-121, 1988.

[25] J. B. Boisvert, Q. H. Gwyn, B. Brisco, D. J. Major and R. J. Brown, "Evaluation of soil moisture estimation techniques and microwave penetration depth for radar applications," Can.J. Remote Sens., vol. 21, no. 2, pp. 110-123, 1995.

[26] M. T. Hallikanen, F. T. Ulaby, M. C. Dobson, M. El-Rayes, and L. Wu, "Microwave dielectric behavior of wet soil- Part I: empirical models and experimental observations," IEEE Trans.Geosci. Remote Sens., vol. GE-23(1), pp. 25-34, 1985.

[27] M. Zribi, O. Taconet, S. Le Hégarat-Mascle, D. Vidal-Madjar, C. Emblanch, C. Loumagne, and M. Normand, "Backscattering behavior and simulation comparison over bare soils using SIRC/XSAR and ERASME 1994 data over Orgeval," Remote Sens. Environ., vol. 59, no. 2, pp. 256-266, 1997.

\section{Acknowledgements}

This study was funded by the French national MISTRALS program, the ANR AMETHYST project, and the French IRD (Development Research Institute = Institut de Recherche pour le Developpement'). The authors wish to thank the DLR and ESA for kindly providing our team withTerraSAR-X SAR data and Envisat ASAR images. The TERRASAR-X images were obtained under proposal HYD0007. Envisat ASAR images were obtained under proposal AOE. 351. We would also wish to thank all of the technical teams of the IRD and INAT for their strong collaboration and support in implementing the ground-truth measurements. 


\section{Figure and Table captions:}

Figure 1: Simulated soil moisture profiles showing temporal and vertical variations in soil moisture, from Prof1 to Prof6.

Figure 2: Penetration depth as a function of soil moisture and radar frequency.

Figure 3. Inter-comparison between 4-layer AIEM model simulations and AIEM simulations with homogeneous conditions (for the first $5 \mathrm{~cm}$ ): a) $\mathrm{L}$ band, b) $\mathrm{C}$ band, c) $\mathrm{X}$ band.

Figure 4. Illustration of the relationship between soil moisture and backscattering coefficients simulated with the AIEM models for different configurations (Case1: 4-layer AIEM model as a function of moisture estimated down to the penetration depth, Case2: 4-layer AIEM model as a function of moisture estimated over the first $5 \mathrm{~cm}$, Case3: single-layer AIEM model as a function of moisture measured over the first $5 \mathrm{~cm}$, (a) L band, (b) $\mathrm{C}$ band, (c) $\mathrm{X}$ band.

Figure 5: Soil moisture contents measured in situ, in the three training fields.

Figure 6: Inter-comparisons between AIEM simulations (using 4-layer and single-layer versions), and real radar data from Envisat ASAR (a) and TerraSAR-X (b)

Table 1: Envisat ASAR and TerraSAR-X acquisition details

Table2: Ground measurement details for the three test fields 


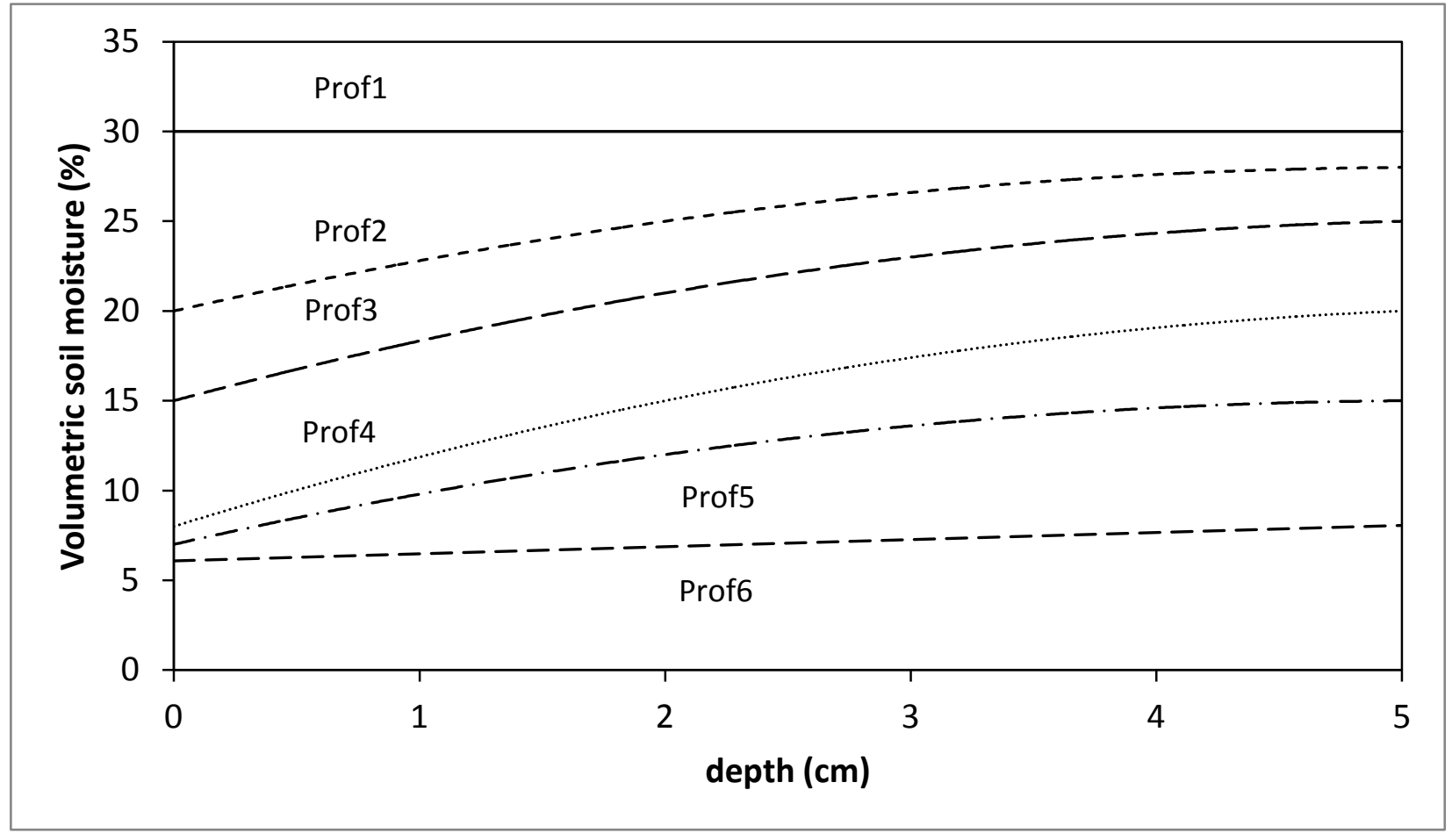

Figure 1: Simulated soil moisture profiles showing temporal and vertical variations in soil moisture, from Prof1 to Prof6. 


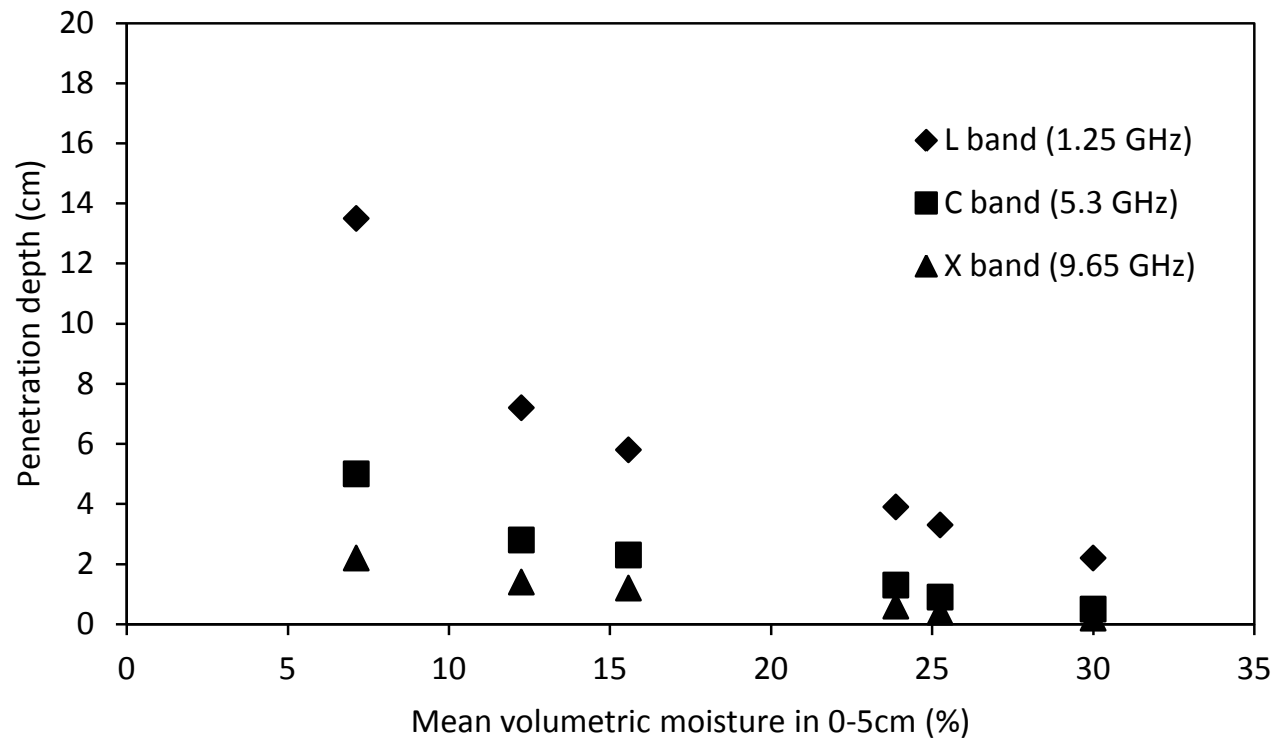

Figure 2: Penetration depth as a function of soil moisture and radar frequency. 


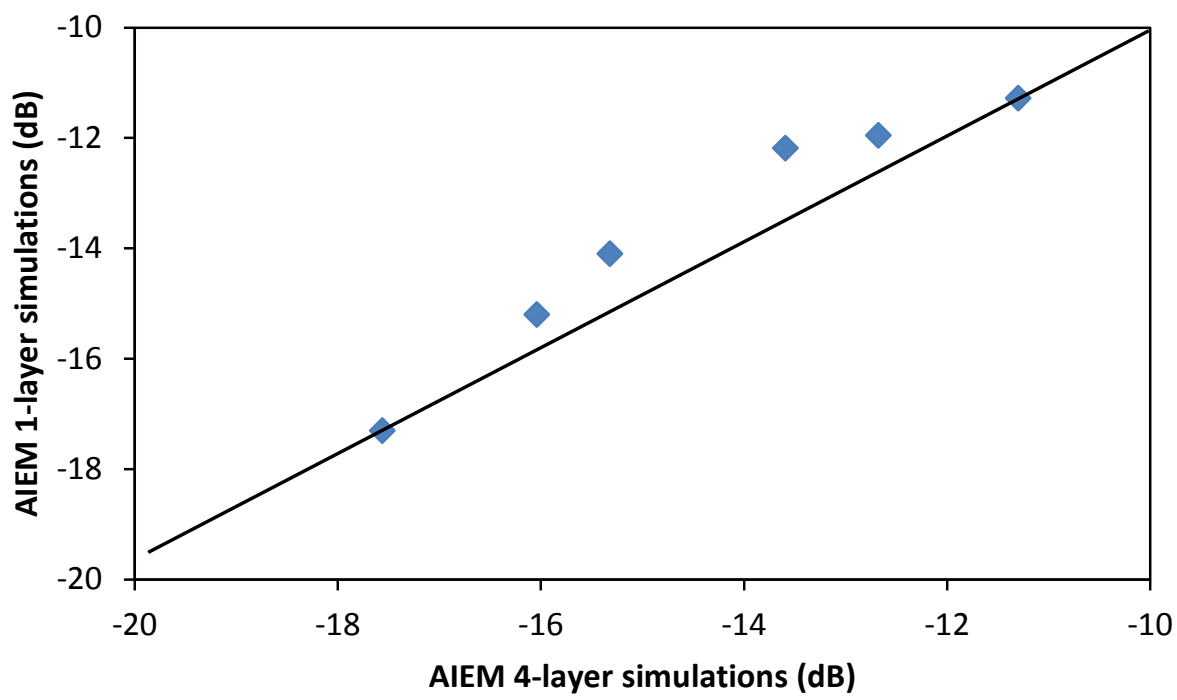

(a)

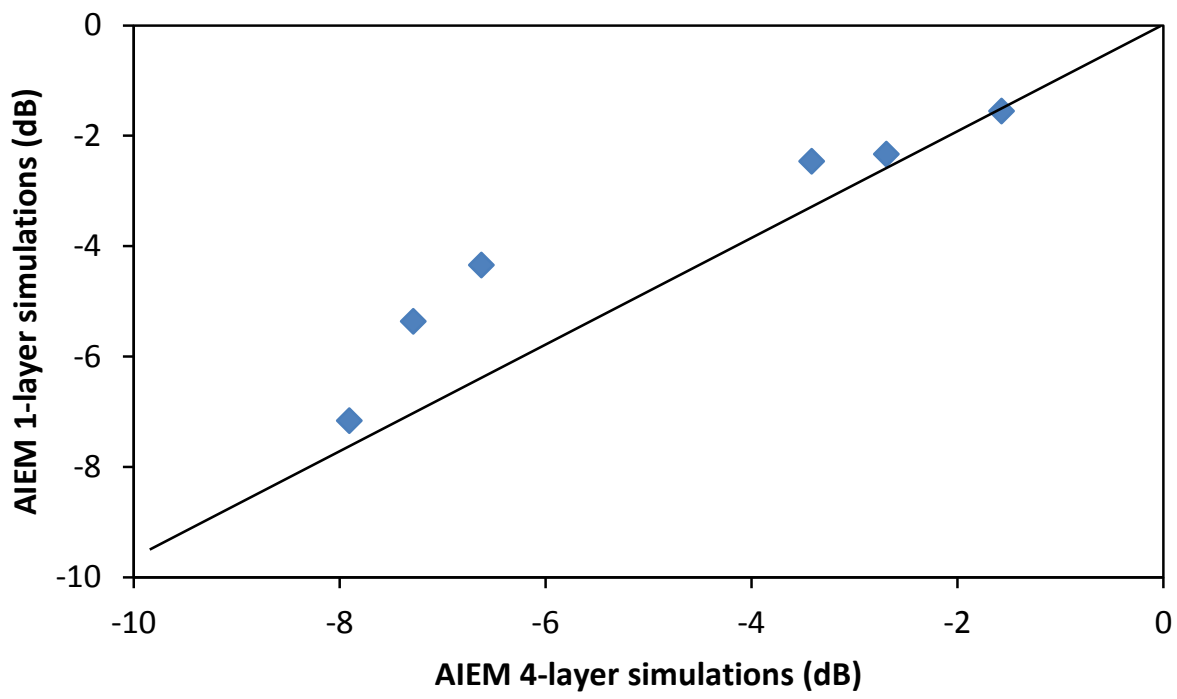

(b) 


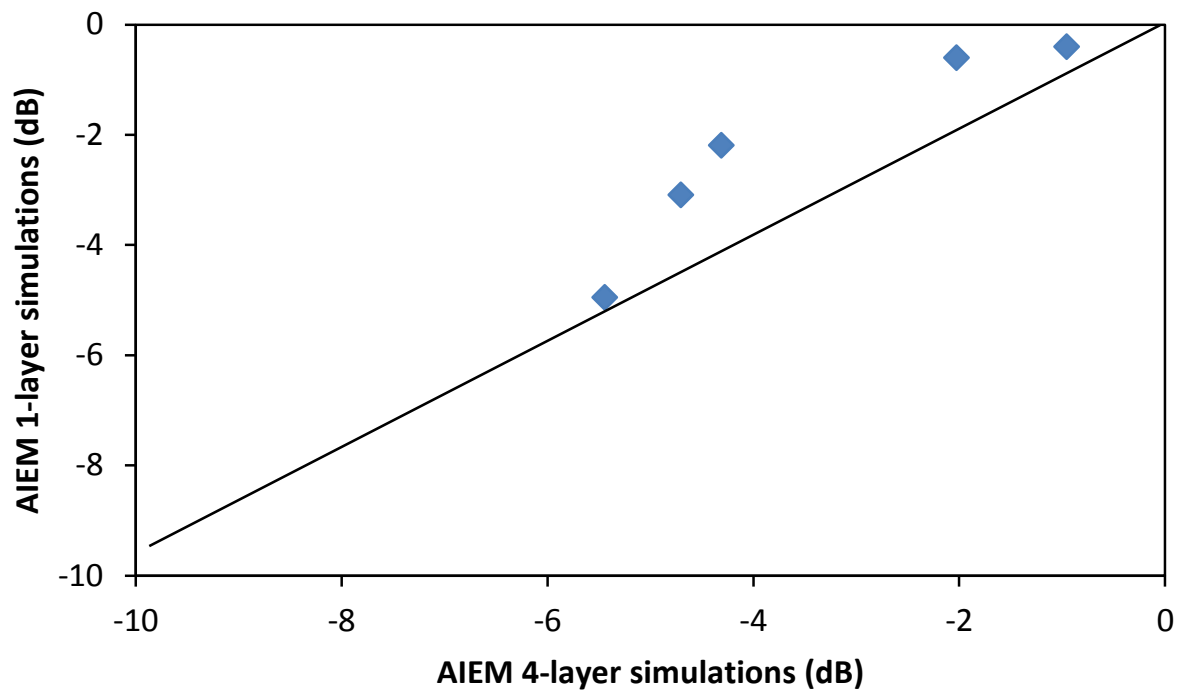

(c)

Figure 3. Inter-comparison between 4-layer AIEM model simulations and AIEM simulations with homogeneous conditions (for the first $5 \mathrm{~cm}$ ): a) $\mathrm{L}$ band, b) $\mathrm{C}$ band, c) $\mathrm{X}$ band. 


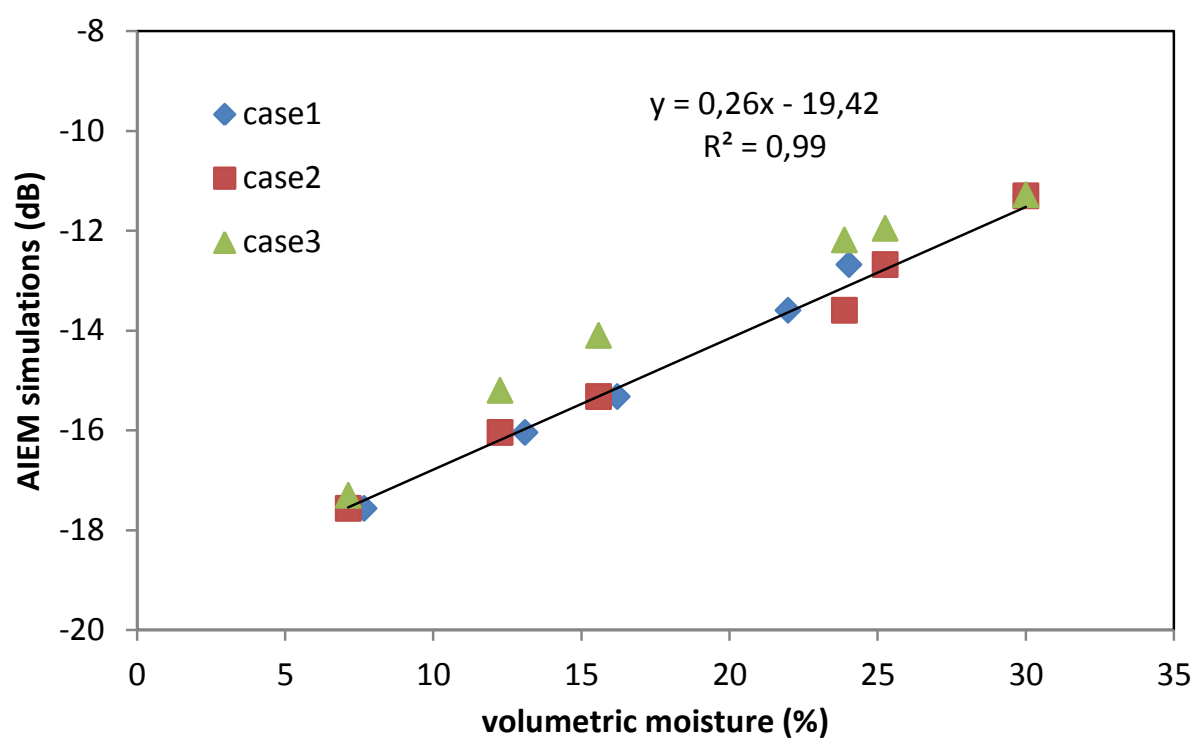

(a)

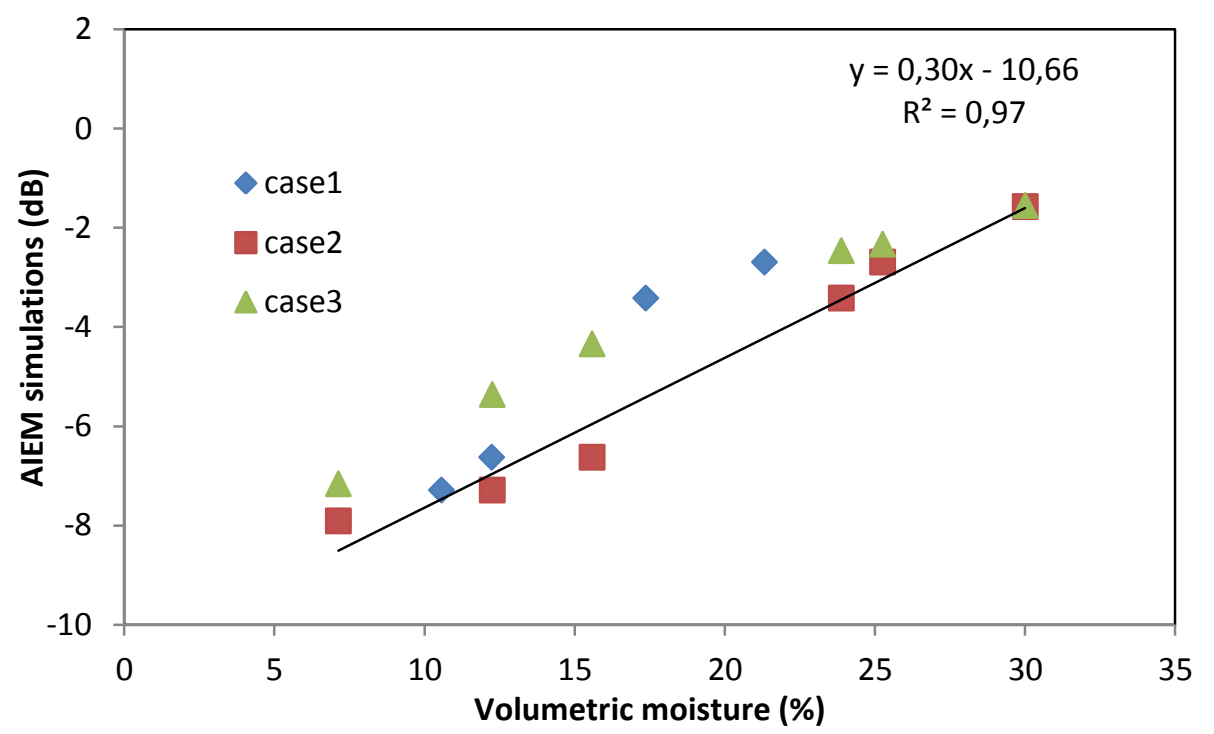

(b) 


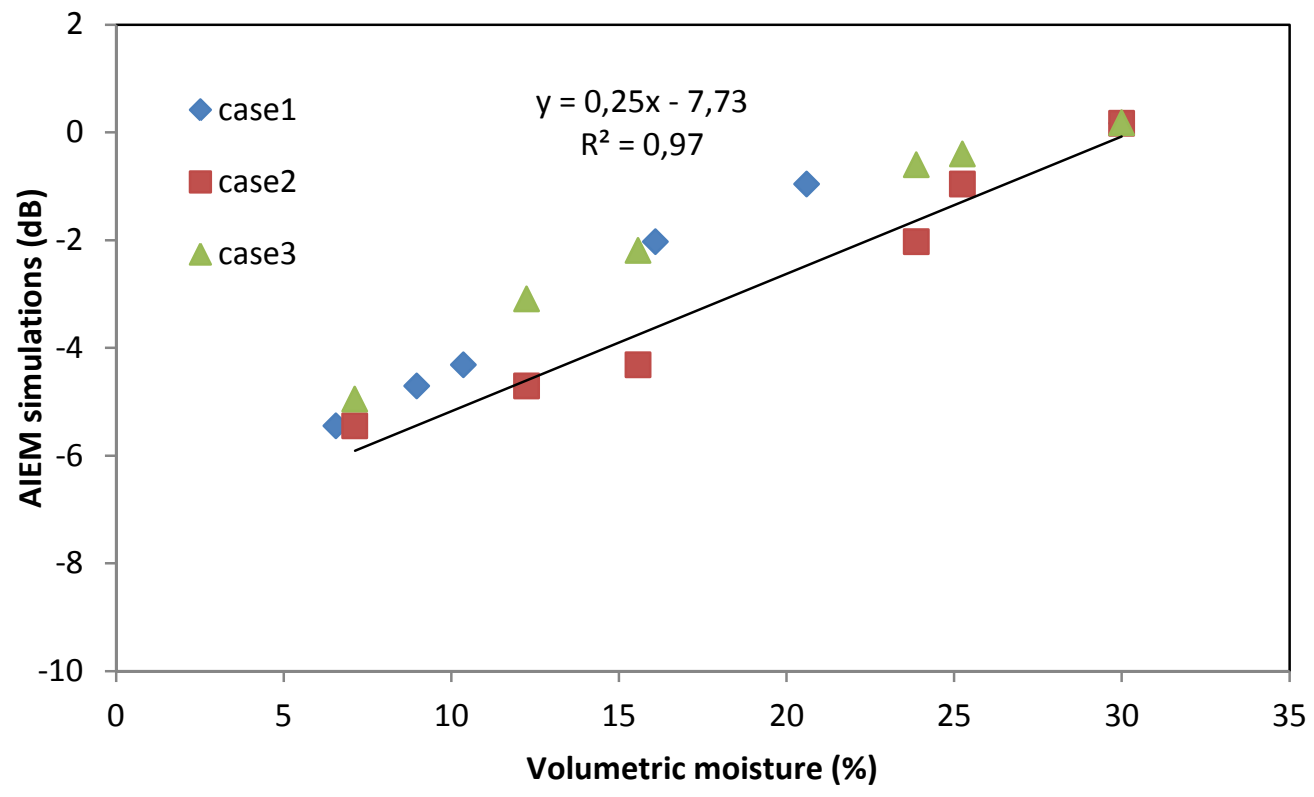

(c)

Figure 4. Illustration of the relationship between soil moisture and backscattering coefficients simulated with the AIEM models for different configurations (Case1: 4-layer AIEM model as a function of moisture estimated down to the penetration depth, Case2: 4-layer AIEM model as a function of moisture estimated over the first $5 \mathrm{~cm}$, Case3: single-layer AIEM model as a function of moisture measured over the first $5 \mathrm{~cm}$, (a) L band, (b) $\mathrm{C}$ band, (c) X band. 

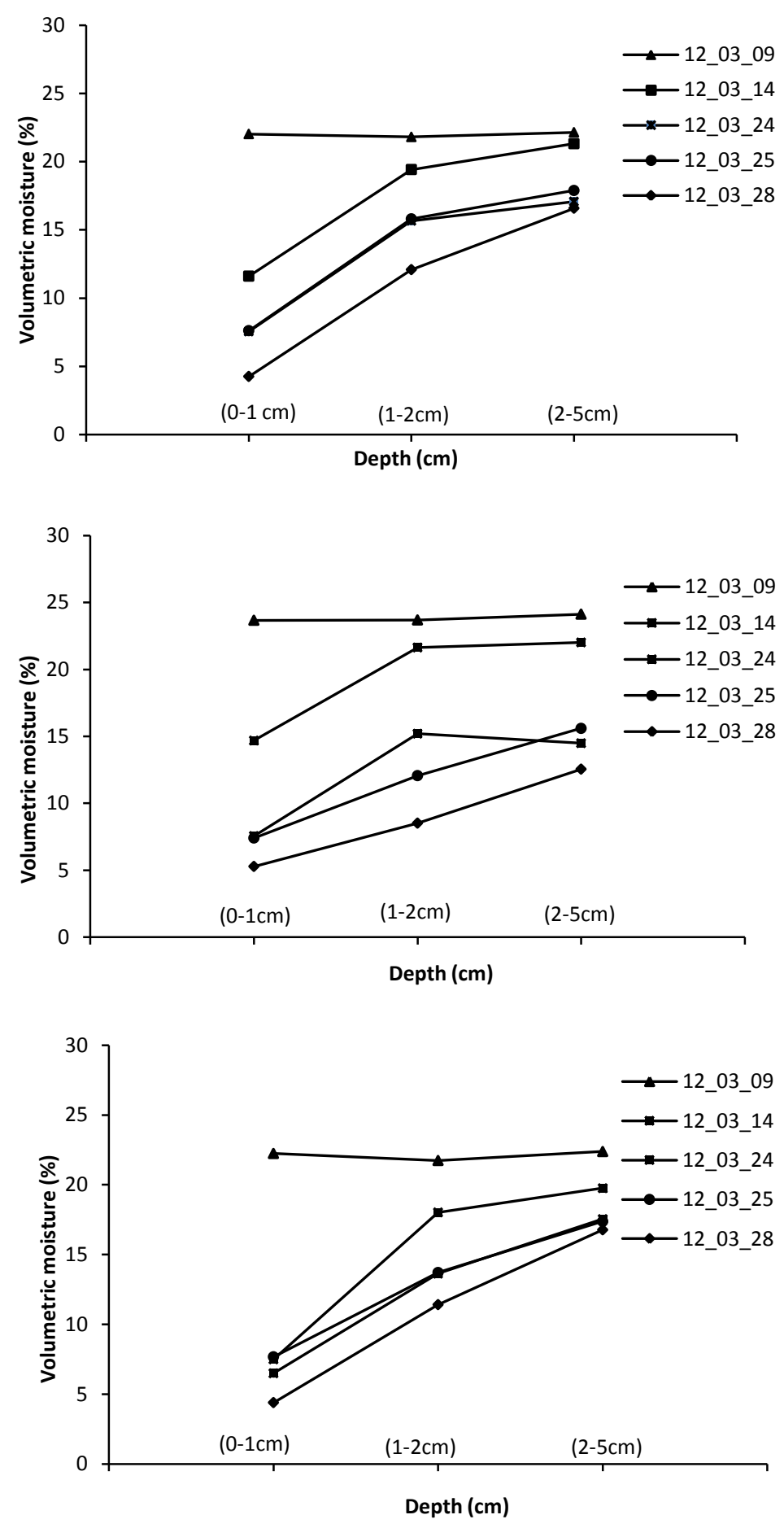

Figure 5: Soil moisture contents measured in situ, in the three training fields. 

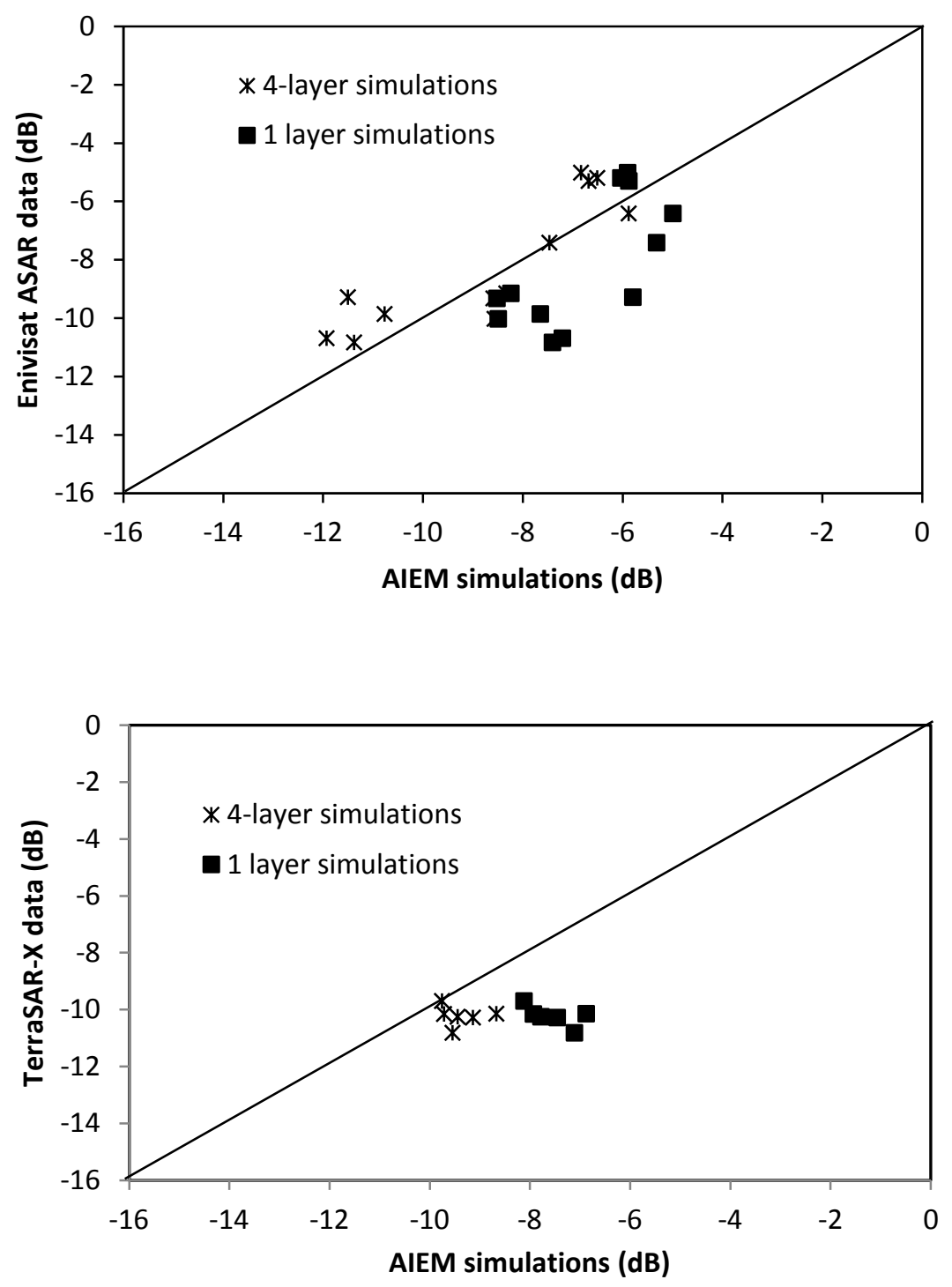

Figure 6: Inter-comparisons between AIEM simulations (using 4-layer and single-layer versions), and real radar data from Envisat ASAR (a) and TerraSAR-X (b) 


\begin{tabular}{|c|c|c|c|}
\hline Sensor & $\begin{array}{l}\text { Acquisition } \\
\text { date }\end{array}$ & Pixel size & configuration \\
\hline Envisat ASAR & $08 / 03 / 2012$ & $12.5 \mathrm{~m} \mathrm{X} 12.5 \mathrm{~m}$ & IS2 $\left(20^{\circ}\right)$ \\
\hline Envisat ASAR & $09 / 03 / 2012$ & $12.5 \mathrm{~m} \mathrm{X} 12.5 \mathrm{~m}$ & IS5 $\left(41^{\circ}\right)$ \\
\hline Envisat ASAR & $14 / 03 / 2012$ & $12.5 \mathrm{~m} \mathrm{X} 12.5 \mathrm{~m}$ & IS1 $\left(15^{\circ}\right)$ \\
\hline Envisat ASAR & $25 / 03 / 2012$ & $12.5 \mathrm{~m} \mathrm{X} 12.5 \mathrm{~m}$ & IS2 $\left(21^{\circ}\right)$ \\
\hline TerraSAR-X & $14 / 03 / 2012$ & $1 \mathrm{mX} 1 \mathrm{~m}$ & $35^{\circ}$ \\
\hline TerraSAR-X & $25 / 03 / 2012$ & $1 \mathrm{mX} 1 \mathrm{~m}$ & $35^{\circ}$ \\
\hline
\end{tabular}

Table 1: Envisat ASAR and TerraSAR-X acquisition details

\begin{tabular}{|l|l|l|l|}
\hline Field & Rms height $(\mathrm{cm})$ & $\begin{array}{l}\text { Correlation length } \\
(\mathrm{cm})\end{array}$ & $\begin{array}{l}\text { Texture } \\
\text { Sand, clay, silt }\end{array}$ \\
\hline F1 & 1.6 & 6.1 & $38 \%, 40 \%, 22 \%$ \\
\hline F2 & 1.1 & 4.2 & $43 \%, 41 \%, 16 \%$ \\
\hline F3 & 1.9 & 3.8 & $35 \%, 43 \%, 22 \%$ \\
\hline
\end{tabular}

Table2: Ground measurement details for the three test fields 